\title{
Effects of Tobacco Smoking on the Hoffmann Reflex
}

Chitoshi Kadoya, M.D., Shigeaki Matsuoka, M.D., and Edward F. Domino, M.D.

Ten normal adult tobacco smoking volunteers 21 to 32 years of age were the subjects of this study. They were asked not to smoke for 12 hours prior to testing. The Hoffmann $(H)$ reflex and its recovery cycle were measured before and just after smoking (on different days) one nonfiltered, zero, low $(0.27 \mathrm{mg})$, or high $(2.16 \mathrm{mg})$ nicotine tobacco cigarette. After smoking the nicotinecontaining cigarettes, the subjects showed a reduction of the $H$ reflex recovery cycle. Individual differences were marked. Nevertheless, the data obtained are consistent with evidence in animals that nicotine and tobacco smoke stimulate Renshaw inhibitory neurons in the spinal cord, either directly or indirectly. This technique provides another objective measure of the effects of tobacco smoking in human volunteers. [Neuropsychopharmacology 9:233-238, 1993]
KEY WORDS: Tobacco smoking; Hoffmann reflex; Recovery cycle

It is well known that tobacco smoking and nicotine reduce the patellar reflex of animals and man (Schweitzer and Wright 1938; Clark and Rand 1964; Domino and von Baumgarten 1969). Another monosynaptic stretch reflex is the ankle jerk, with an electrically evoked monosynaptic response that is equivalent to the Hoffmann $(\mathrm{H})$ reflex. Gassel (1973) reported in a nonpeerreviewed

$0.8 \mathrm{mg}$ to $1 \mathrm{mg}$ of nicotine in either 24-hour deprived smokers or nonsmokers caused a concomitant decrease in the ankle jerk as well as the conditioning and test $\mathrm{H}$ reflex recovery cycle at 200 - and 300 -millisecond intervals. Recovery occurred within 30 minutes. The present study was designed to determine the effects of smoking cigarettes of a wider range of nicotine content on the $\mathrm{H}$ reflex recovery cycle over a much longer 60 to 340-millisecond interval. Arterial blood pressure and

From the Department of Pharmacology (CH, EFD), University of Michigan, Ann Arbor, Michigan and Department of Neurosurgery ( $\mathrm{CH}, \mathrm{SM})$, University of Occupational and Environmental Health, Kitakyushu, Japan.

Address all correspondence to: E.F. Domino, M.D., Department of Pharmacology, University of Michigan, Ann Arbor, MI 48109-0626. Received February 23, 1993; revised June 29, 1993; accepted June 30, 1993. heart rate were also measured as a control index of peripheral vascular effects.

\section{SUBJECTS AND METHODS}

Ten healthy normal tobacco cigarette smoking volunteers who inhaled and smoked at least one pack of cigarettes per day were recruited for this study. They ranged in age from 21 to 32 years with a mean of 22.8 years. Two were women and eight were men. They were asked to stop smoking the night before each experiment so that they would be approximately 12 hours without cigarette smoking at the time of each test.

Approximately 12 hours after the last tobacco cigarette smoked, each subject, in a random design, was asked to smoke three different nonfiltered cigarettes on different days in the laboratory. The cigarettes contained no $(0 \mathrm{mg})$, low $(0.27 \mathrm{mg})$, or high nicotine $(2.16$ $\mathrm{mg}$ ). The nicotine-free cigarettes were purchased over the counter and contained a blend of wheat, cocoa and orange leaves. The low- and high-nicotine cigarettes were research cigarettes obtained from the University of Kentucky (2R1; Tobacco and Health Research Institute, Lexington, KY). Each subject smoked the cigarettes at their normal rate, depth of inhalation, and duration of 5 to 8 minutes. The mean of two presmoking 
and two postsmoking $\mathrm{H}$ reflex recovery cycles was determined for each subject. In addition, heart rate and blood pressure were measured before and after smoking by feeling the pulse and by auscultation, respectively. Data were analyzed using both correlated and noncorrelated Student $t$-tests.

The general methods used for obtaining the H reflex are well described by Hugon (1973). A Nicolet Pathfinder II was used in these studies. The amplifier bandpass was $75 \mathrm{~Hz}$ to $1500 \mathrm{~Hz}$. Stimulus S1 was applied to the left popliteal space for stimulating the posterior tibial nerve with a bipolar electrode. The cathode was placed centrally and the anode distally. A square-wave pulse of 0.5 milliseconds every 2 seconds was applied. The subject's motor response of the calf (soleus) muscle was recorded as the direct $M$ response. At the site of maximal response, a bipolar EMG electrode was placed over the soleus muscle with a ground between the stimulating and the recording electrodes. The stimulating and recording electrodes were placed so that a maximal $\mathrm{H}$ response was obtained with a minimal $\mathrm{M}$ response from the normally relaxed soleus muscle. The Nicolet was programmed to provide 16 channels of data. Channel 1 always displayed only the first $\mathrm{H}$ response $(\mathrm{H} 1)$. The second $\mathrm{H}$ response $(\mathrm{H} 2)$ was displayed along with the first on the 15 other channels. The $\mathrm{H} 1$ and $\mathrm{H} 2$ responses were separated at increasing 20 -millisecond intervals. Thus, $\mathrm{S} 2$ would be elicited after S1 at intervals of $60,80,100,120,140,160$, and so on milliseconds. The data obtained were expressed as

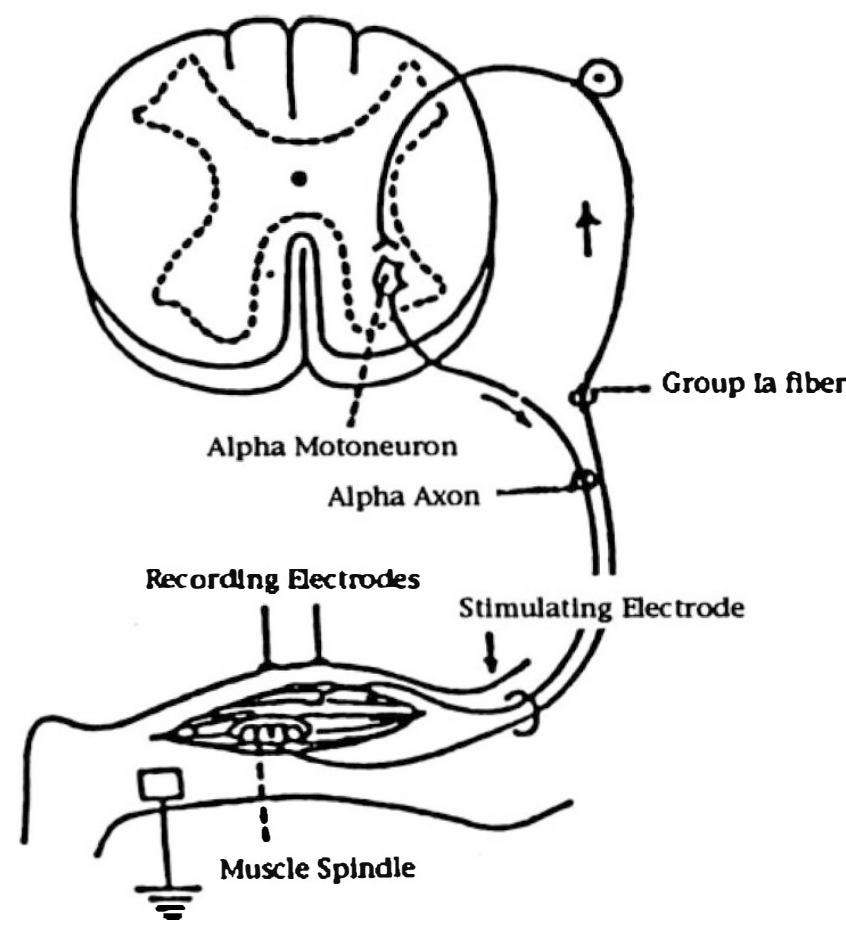

Figure 1. Schematic diagram of the neural pathways involved in the $\mathrm{H}$ reflex. the ratio of the amplitude of the $\mathrm{H} 2$ to the $\mathrm{H} 1$ response at different millisecond intervals from 60 to 340 to determine the recovery cycle. Figure 1 illustrates the spinal reflex pathway studied. Figure 2 illustrates typical potentials of the $\mathrm{M}$ and $\mathrm{H}$ responses as recorded.

\section{RESULTS}

\section{Effects on the Recovery Cycle of the H Reflex}

Smoking a nicotine-free cigarette had no significant effect on the recovery cycle of the $\mathrm{H}$ reflex. The recovery cycle for all 10 subjects is illustrated in Figure 3 and is given to show normal intersubject variability. In contrast, in most subjects smoking a low- or high-nicotine cigarette produced some depression of the recovery cycle of the $\mathrm{H}$ reflex. Smoking a low-nicotine cigarette depressed the $\mathrm{H}$ reflex only at certain intervals, particularly in subjects SE, IK, OK, MA, OM, and KN. In contrast, smoking a high-nicotine cigarette depressed the $\mathrm{H}$ reflex at more intervals in subjects $\mathrm{YA}, \mathrm{SE}, \mathrm{IK}$, $\mathrm{MR}, \mathrm{OK}, \mathrm{MA}, \mathrm{OM}$, and OS. The mean ratio of the $\mathrm{H} 2 / \mathrm{H} 1$ amplitude was obtained for all 10 subjects smoking cigarettes of differing nicotine concentrations. A dose-effect relationship to nicotine existed in which smoking the nicotine-free cigarette had no significant effect on the mean $\mathrm{H}$ reflex recovery cycle, but it was progressively reduced after smoking the low- and especially the high-nicotine-containing cigarette. The mean data are illustrated in Figure 4. The differences were statistically significant at many different stimulus intervals of the recovery cycle $(p<.05)$.

\section{Cardiovascular Effects of Tobacco Smoking}

Smoking cigarettes of differing nicotine content had either no effect or caused a slight increase in heart rate and arterial blood pressure. As can be seen in Figure 5 , smoking nicotine-free cigarettes had no effect on

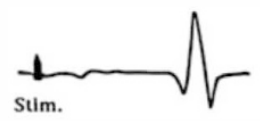

M

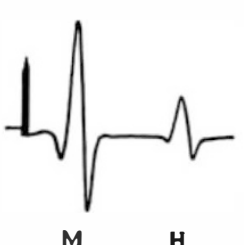

H

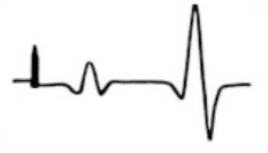

H

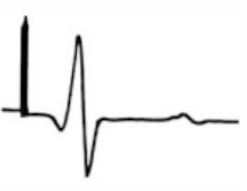

M

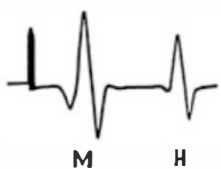

Figure 2. $\mathrm{M}$ and $\mathrm{H}$ electromyographs of the soleus muscle illustrating the effects of increasing stimulus strength on the relative size of the $\mathrm{M}$ and $\mathrm{H}$ electromyographic response. In the present study, the intensity of the electrical stimulus was reduced for a minimum $\mathrm{M}$ and maximum $\mathrm{H}$ response. 
Y. A.
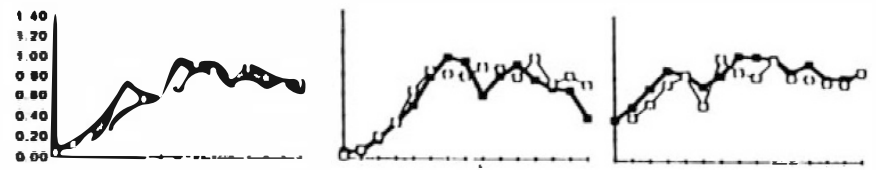

S. E.
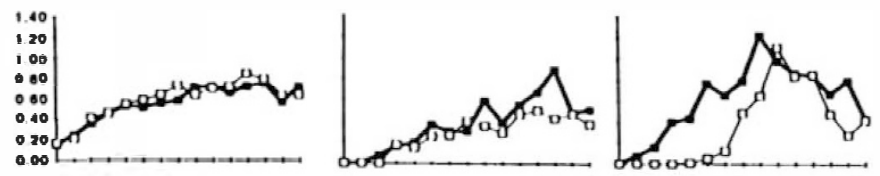

I. $K$
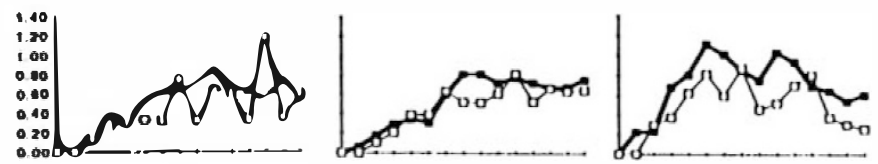

M. R.
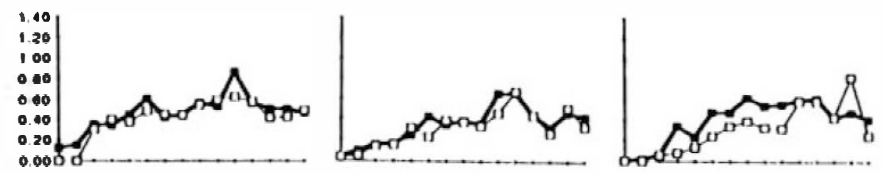

o. $K$
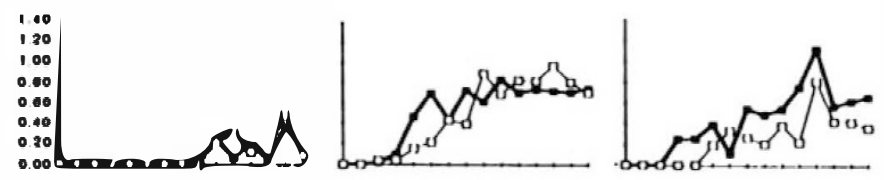

M. A.
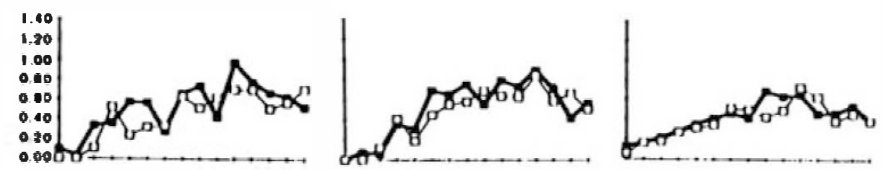

O. $M$
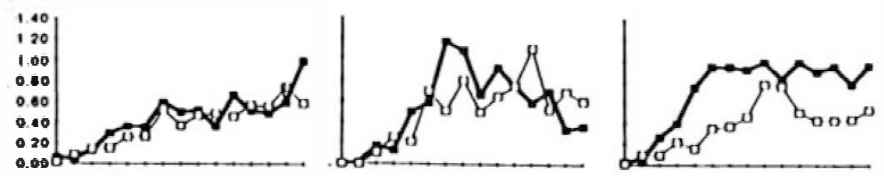

K. H.
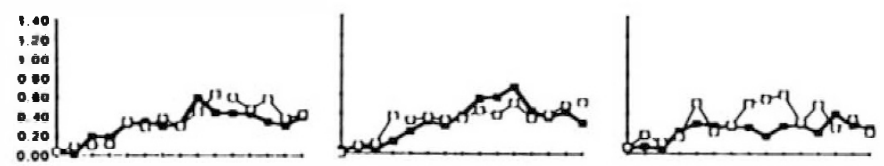

$K N$.
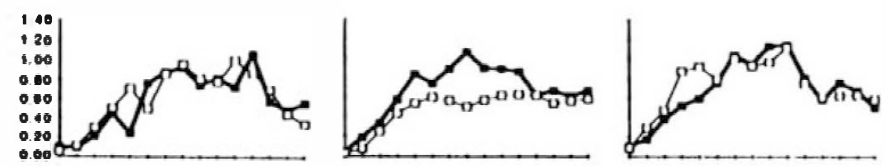

o.s.
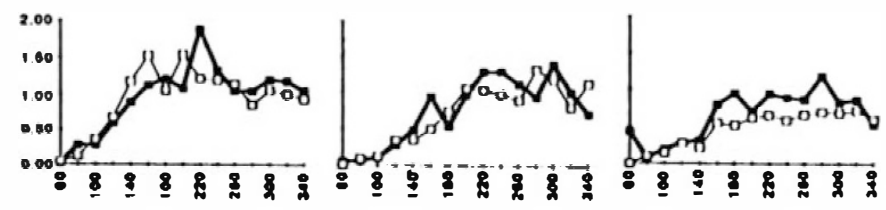
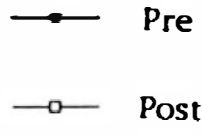

Figure 3. Effects of smoking tobacco of differing nicotine content on the recovery cycle of the Hoffmann reflex in 10 individual smokers.

The stimulus interval between S1 and S2 is plotted on the x-axis. The mean ratio of the amplitude of the $\mathrm{H} 2 / \mathrm{H} 1$ reflex is plotted on they-axis. Each subject was studied on three different days on which a free- $(0 \mathrm{mg})$, low- $(0.27 \mathrm{mg})$, or high(2.16 mg) nicotine content cigarette was smoked. Each horizontal row of the three graphs illustrates the data for one subject identified by his or her initials. The left vertical column of graphs represents the recovery cycle plotted for each of 10 subjects smoking a nicotinefree cigarette. The middle vertical column represents the $\mathrm{H}$ reflex recovery cycle obtained from the same individuals smoking a lownicotine-containing cigarette. The vertical column of graphs on the right represents the $\mathrm{H}$ reflex effects in the same individuals smoking a high-nicotine-containing cigarette. 
Figure 4. The effects of smoking tobacco of differing nicotine content on the mean recovery cycle of the $\mathrm{H}$ reflex.

The mean data of the recovery cycle of the $\mathrm{H}$ reflex are plotted for 10 individuals smoking nicotinefree, low- (0.27 mg), and high- (2.16 $\mathrm{mg})$ nicotine-containing cigarettes. The $x$ - and $y$-axes of each of the graphs are similar to those described in Figure 3. The data are statistically significant using a twotailed paired comparison $t$ test. The vertical lines represent $\pm \mathrm{SE} .{ }^{\star} p<$ $.05,{ }^{\star \star} p<.01$.
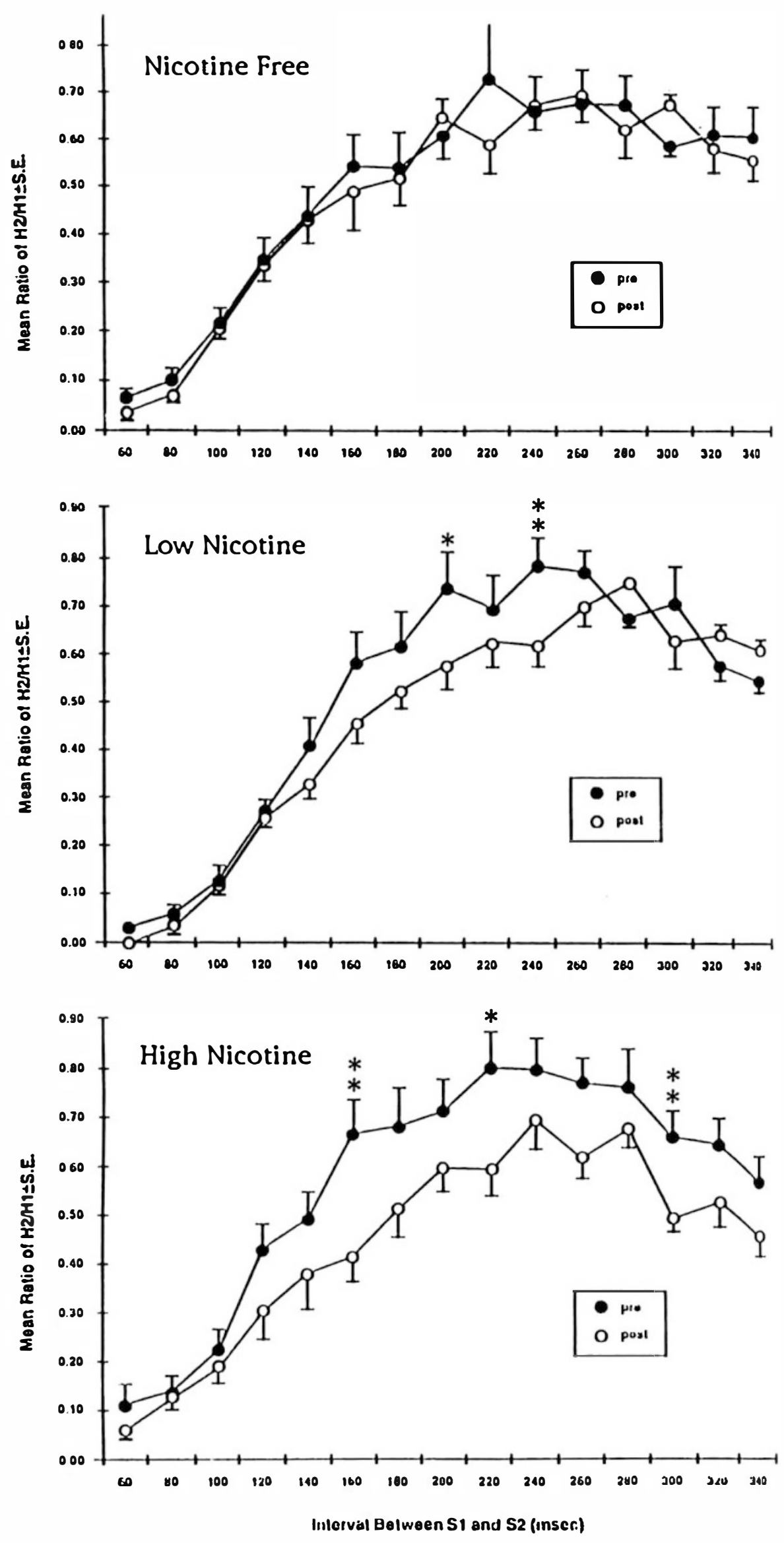

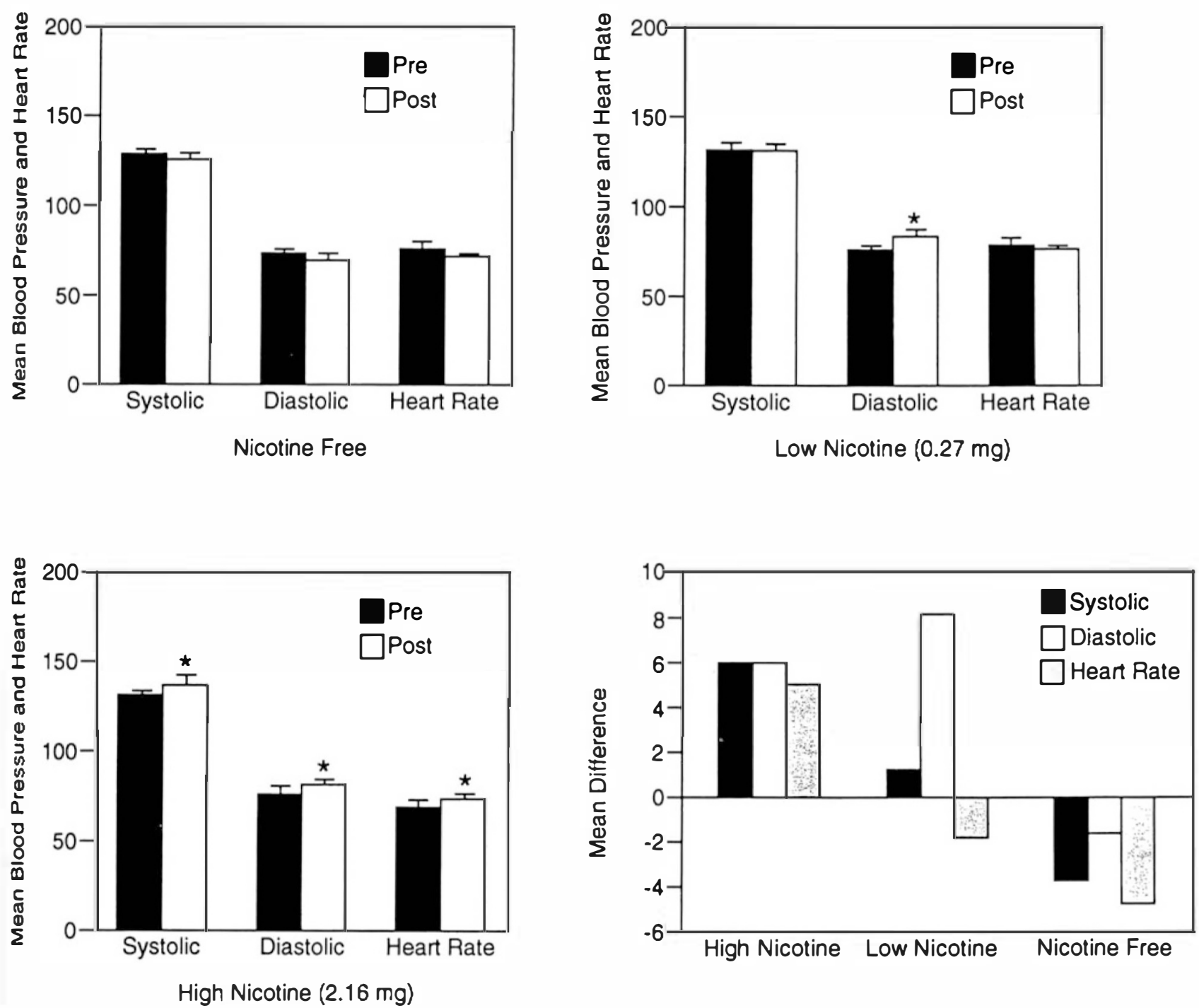

Figure 5. Mean cardiovascular effects of smoking tobacco of differing nicotine content. The mean systolic and diastolic arterial blood pressure and the heart rate are plotted. The vertical lines represent $+\mathrm{SE} .{ }^{\star} p<.05$.

mean systolic or diastolic blood pressure and heart rate. In contrast, smoking the low-nicotine cigarette produced a slight increase in diastolic blood pressure whereas smoking the high-nicotine-containing cigarette slightly elevated systolic and diastolic blood pressure and heart rate.

\section{DISCUSSION}

The results of this study indicate that the recovery cycle of the $\mathrm{H}$ reflex is clearly depressed following the smoking of tobacco-containing cigarettes. There is a dose-effect relationship in that smoking a zero-nicotine-containing cigarette had no significant effect on the recovery cycle of the $\mathrm{H}$ reflex as opposed to low- or highnicotine-containing tobacco cigarettes. The data of the present study are in complete agreement with Gassel
(1973) who determined the effects of tobacco smoke in 10 studies and the effects of intravenous nicotine $(0.8$ $\mathrm{mg}$ to $1.0 \mathrm{mg}$ ) in four studies. It was not clear from his report whether each study represented a separate subject. Both treatments caused a marked depression of the $\mathrm{H}$ reflex and its excitability. His subjects were nonsmokers or were tobacco smokers who stopped smoking at least 24 hours before each test. The nicotine content of the cigarette was not specified. He measured the $\mathrm{H}$ reflex recovery cycle at only 200 - and 300 -millisecond intervals. At both intervals, there was a dramatic suppression to approximately $50 \%$ of control. This effect was consistent with a similar depression of the ankle jerk. The overall effect lasted approximately 20 to 30 minutes following either tobacco smoking or nicotine administration.

In the present study, there was considerable individual variation in the effects observed. This is evi- 
dent from the summary graphs of the actual data of all 10 subjects under three different conditions of smoking tobacco of varying nicotine content. This may be related, in part, to the fact that the subjects smoked at their own pace, as they would normally. Whether the effects of the inhaled nicotine act directly on the spinal cord or on inputs from peripheral sites is a subject of future study. There is no question that nicotine itself has a direct action to suppress the patellar reflex by stimulation of Renshaw inhibitory neurons in the spinal cord (Eccles et al. 1954; Curtis and Ryall 1964; Ueki et al. 1961). Ginzel (1967) suggested that nicotine also excites a variety of peripheral sites including a large variety of peripheral chemoreceptors and sensory receptors such as the muscle spindle, which provide additional inputs that stimulate Renshaw inhibitory neurons and thus indirectly act to suppress the recovery cycle of the $\mathrm{H}$ reflex.

Irrespective of whether the site of action of nicotine is peripheral or central, it is clear that the present data support the notion that smoking tobacco cigarettes of adequate nicotine content has important actions on the spinal cord $\mathrm{H}$ reflex recovery cycle. The implications of this research are that humans who smoke tobacco receive a skeletal muscle relaxant effect. Webster (1964) reported that tobacco smoking reduced spasticity in a patient with progressive familial spastic paraplegia, as measured quantitatively using passive motion resistance. It would be of interest to do additional studies with nicotine gum or patch to determine whether there is any significant tachyphylaxis or tolerance with continued nicotine administration.

The cardiovascular effects of tobacco smoking were relatively negligible in this study. Only after smoking cigarettes containing the highest concentration of nicotine were statistically significant but small changes observed in systolic and diastolic blood pressure and heart rate. The significance of this finding is that the plasma levels of nicotine after smoking must have been relatively low and yet definite effects were observed on the $\mathrm{H}$ reflex recovery cycle. Further studies correlating plasma levels of nicotine with the $\mathrm{H}$ reflex recovery cycle after tobacco smoking are indicated and are now being pursued.

\section{ACKNOWLEDGMENT}

Funding for this investigation was provided in part by NIDA Grant DA 07226.

\section{REFERENCES}

Clark MSG, Rand MJ (1964): A pharmacological effect of tobacco smoke. Nature 102:507-508

Curtis RD, Ryall RW (1964): Nicotine and muscarinic receptors of Renshaw cells. Nature 203:652-653

Domino EF, von Baumgarten AM (1969): Tobacco cigarette smoking and patellar reflex depression. Clin Pharmacol Ther 10:72-79

Eccles JC, Fatt P, Koketsu K (1954): Cholinergic and inhibitory synapses in a pathway from motor-axon collaterals to motoneurons. J Physiol (Lond) 126:524-562

Gassel MM (1973): An objective technique for the analysis of the clinical effectiveness and physiology of action of drugs in man. In Desmedt JE (ed), New Developments in Electromyography and Clinical Neurophysiology. Basel, Karger, pp 342-359

Ginzel KH (1967): Introduction to the effects of nicotine on the central nervous system. Ann NY Acad Sci 142:101-120

Hugon M (1973): Methodology of the Hoffmann reflex in man. In Desmedt JE (ed), New Developments in Electromyography and Clinical Neurophysiology, Vol 3. Basel, Karger, pp 277-293

Schweitzer A, Wright S (1938): Action of nicotine on the spinal cord. J Physiol 94:136-147

Ueki S, Koketsu K, Domino EF (1961): Effects of mecamylamine on the Golgi recurrent collateral-Renshaw cell synapse in the spinal cord. Exp Neurol 3:141-148

Webster DD (1964): The dynamic quantification of spasticity with automated integrals of passive motion resistance. Clin Pharmacol Ther 5:900-908 